\title{
Structure-activity relationships of mononuclear metal-thiosemicarbazone complexes endowed with potent antiplasmodial and antiamoebic activities
}

\author{
Deepa Bahl ${ }^{\mathrm{a}}$, Fareeda Athar ${ }^{\mathrm{b}}$, Milena Botelho Pereira Soares ${ }^{\mathrm{c}, \mathrm{d}}$, Matheus Santos de Sá ${ }^{\mathrm{c}}$, \\ Diogo Rodrigo Magalhães Moreira ${ }^{\mathrm{e}}$, Rajendra Mohan Srivastava ${ }^{\mathrm{e}}$, Ana Cristina Lima Leite ${ }^{\mathrm{f}, *}$, Amir Azam ${ }^{\mathrm{a}, *}$ \\ a Department of Chemistry, Jamia Millia Islamia, Jamia Nagar, New Delhi 110025, India \\ ${ }^{\mathrm{b}}$ Centre for Interdisciplinary Research in Basic Sciences, Jamia Millia Islamia, New Delhi 110025, India \\ ${ }^{c}$ Center of Research Gonçalo Moniz, Oswaldo Cruz Foundation, Rua Waldemar Falcão, 121, Candeal, Salvador 40296-710, BA, Brazil \\ ${ }^{\mathrm{d}}$ São Rafael Hospital, Av. São Rafael, 2152, São Marcos, Salvador 41253-190, BA, Brazil \\ e Department of Fundamental Chemistry, Centre for Natural Sciences (CCEN), Federal University of Pernambuco, 50740-540 Recife, PE, Brazil \\ ${ }^{\mathrm{f}}$ Department of Pharmaceutical Sciences, Centre for Health Sciences, Federal University of Pernambuco, 50740-520 Recife, PE, Brazil
}

\section{A R T I C L E I N F O}

\section{Article history:}

Received 10 July 2010

Accepted 16 July 2010

Available online 21 July 2010

\section{Keywords:}

Antiparasitic drugs

DNA

Entamoeba histolytica

Metal complexes

Plasmodium falciparum

Thiosemicarbazones

\begin{abstract}
A B S T R A C T
A useful concept for the rational design of antiparasitic drug candidates is the complexation of bioactive ligands with transition metals. In view of this, an investigation was conducted into a new set of metal complexes as potential antiplasmodium and antiamoebic agents, in order to examine the importance of metallic atoms, as well as the kind of sphere of co-ordination, in these biological properties. Four functionalized furyl-thiosemicarbazones (NT1-4) treated with divalent metals ( $\mathrm{Cu}, \mathrm{Co}, \mathrm{Pt}$, and $\mathrm{Pd}$ ) to form the mononuclear metallic complexes of formula $\left[\mathrm{M}(\mathrm{L})_{2} \mathrm{Cl}_{2}\right]$ or $\left[\mathrm{M}(\mathrm{L}) \mathrm{Cl}_{2}\right]$ were examined. The pharmacological characterization, including assays against Plasmodium falciparum and Entamoeba histolytica, cytotoxicity to mammalian cells, and interaction with pBR 322 plasmid DNA was performed. Structure-activity relationship data revealed that the metallic complexation plays an essential role in antiprotozoal activity, rather than the simple presence of the ligand or metal alone. Important steps towards identification of novel antiplasmodium (NT1Cu, IC $\mathrm{I}_{50}$ of $4.6 \mu \mathrm{M}$ ) and antiamoebic (NT2Pd, $\mathrm{IC}_{50}$ of $0.6 \mu \mathrm{M}$ ) drug prototypes were achieved. Of particular relevance to this work, these prototypes were able to reduce the proliferation of these parasites at concentrations that are not cytotoxic to mammalian cells.
\end{abstract}

(c) 2010 Published by Elsevier Ltd.

\section{Introduction}

According to the World Health Organization (WHO), there are 300-500 million clinical cases of malaria each year, resulting in an alarming rate of about 1.5-2.0 million deaths annually. ${ }^{1}$ However, it is estimated that this death rate is likely to increase further because of the high level of drug resistance to most of the clinically used antimalarials. ${ }^{2}$ Given the evidence of the global spread of drug resistance, ${ }^{3}$ there is a need for the identification of new antiplasmodial drugs. After malaria, amebiasis (caused by Entamoeba histolytica) is the second leading cause of death from a protozoan parasite. ${ }^{4}$ Metronidazole, the only WHO-recommended drug for treating amebiasis, is toxic and of questionable effectiveness in eliminating the parasite. ${ }^{5}$ New safe and affordable amoebicidal drugs are therefore also urgently needed.

The elucidation of metabolic pathways of fundamental importance (e.g., fatty acid biosynthesis ${ }^{6}$ and heme detoxification ${ }^{7}$ ) and

\footnotetext{
* Corresponding authors. Tel.: +91 11 26981717x3250; fax: +91 1126980229 (A.A.).

E-mail addresses: acllb2003@yahoo.com.br (A.C.L. Leite), amir_sumbul@yahoo. co.in (A. Azam).
}

of valid molecular targets, such as the falcipain- $2,{ }^{8} \mathrm{CDK},{ }^{9}$ purine nucleoside phosphorylases, ${ }^{10}$ and protein serine/threonine phosphatases ${ }^{11}$ of Plasmodium falciparum have contributed to more rational design of drug candidates. In combination with this knowledge, the employment of modern concepts of medicinal chemistry, such as bioisosterism, ${ }^{12}$ molecular hybridization, ${ }^{13}$ bioinspired design in potent hit-compounds, ${ }^{14}$ and the metallic complexation of plasmodicidal compounds ${ }^{15}$ have accelerated the discovery of antiplasmodium drug candidates.

A significant number of transition metal-containing compounds have been either recently launched on the pharmaceutical market or entered into clinical trials, as exemplified by Ferrocifen, NAMI-A, Picoplatin, Ferroquine, and AMD3100. ${ }^{16}$ In the specific case of antiplasmodium agents, in addition to Ferroquine that has recently entered in clinical trial, other metallic structures (complexes of co-ordination and organometallics) have shown promising in vitro and in vivo properties (Fig. 1). ${ }^{17}$ It can thus be concluded that one successful drug development strategy is the complexation of transition metals with plasmodicidal agents, as it is possible to enhance the pharmacological and chemical properties (such as potency, selectivity, chemical stability, and lipophilicity) of the antiplasmodium agent employed. 
<smiles></smiles>

Ferroquine ${ }^{[16 \mathrm{~d}]}$<smiles></smiles>

Cu-naphthoquinone $e^{[17 \mathrm{~d}]}$

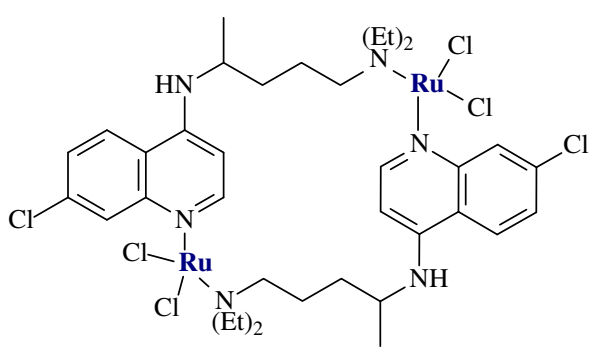

Ru-chloroquine ${ }^{[17 c]}$

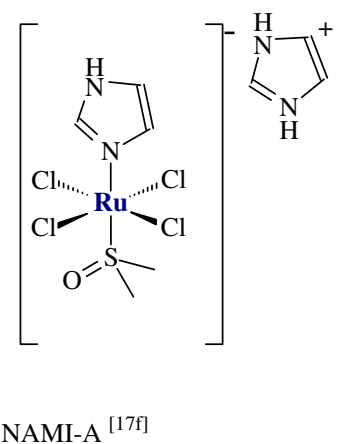

Figure 1. Examples of metallic compounds endowed with potent anti-Plasmodium falciparum activity.

Studies of thiosemicarbazone-based libraries have proved that they are useful ligands for the building of metal complexes with a wide variety of biological targets, including protozoan parasites. $^{8,18}$ Such ligands constitute an ideal source of bioactive ligands because they are endowed with the unique capacity of metallic co-ordination, semi-labile, chemically stables, and are synthetically treatable-features which make them suitable for performing structure-activity relationships (SAR) studies. ${ }^{19}$ It is thus reasonable to believe that thiosemicarbazones are authentic privileged structures. ${ }^{20}$

According to this line of reasoning, metal-thiosemicarbazone complexes previously developed by us were found to improve anti-E. histolytica activity against the HK-9 and HM1:1MSS strains, when compared to the metal-free thiosemicarbazones. ${ }^{21}$ On the one hand, we demonstrated that the cyclic bioisosters of thiosemicarbazones (thiocarboxamide-2-pyrazolines) are less effective against $E$. histolytica than thiosemicarbazones, suggesting that the replacement of a flexible backbone by a more rigid backbone results in a distinct interaction with the protozoan targets. ${ }^{22}$ Moreover, insertion of bulk groups at the 4-position of thiosemicarbazones helps to improve the chemical stability of metal complexes and their lipophilicity, resulting in more potent antiamoebic complexes (Fig. 2). ${ }^{23}$ Although there is a large number of thiosemicarbazones endowed with antiplasmodium activity, ${ }^{24}$ investigations of the antiplasmodium activities for complexes of co-ordination containing thiosemicarbazones are scarce. ${ }^{25}$
In light of these findings, we decided to investigate the antiprotozoal properties of a new set of mononuclear metal-thiosemicarbazone complexes. In our design, the furfuryl ring was explored, in view of previous observation of its antiparasitic properties. ${ }^{26} \mathrm{We}$ have excluded attachment of the nitro group, as it is well-known that this induces toxicity, which is a drawback of the medicinal chemistry of antiparasitic drugs. ${ }^{26 c}$ Later, we selected platinum, palladium, cobalt, and copper, in search of complexes bearing one $\left(\mathrm{MLCl}_{2}\right)$ or two $\left(\mathrm{ML}_{2} \mathrm{Cl}_{2}\right)$ ligands on each co-ordination sphere, thereby aiming to investigate how the ligand sphere contributes to antiprotozoal activity. Therefore, the main achievement of this study was to have gathered, for the first time, valuable SAR data on antiprotozoal metal-thiosemicarbazone complexes.

\section{Results}

\subsection{Synthesis and general remarks of structural elucidation}

The synthesis of ligands NT1-4 was straightforward and proceeded moderate to good yields (41-90\%). NT1-4 were further used as chelating ligands to complex with $\left[\mathrm{Pd}(\mathrm{DMSO})_{2} \mathrm{Cl}_{2}\right.$ ], [ $\mathrm{Pt}(\mathrm{DMSO})_{2} \mathrm{Cl}_{2}$ ], $\mathrm{CoCl}_{2} \cdot 6 \mathrm{H}_{2} \mathrm{O}$ or $\mathrm{CuCl}_{2} \cdot 2 \mathrm{H}_{2} \mathrm{O}$ to generate the respective mononuclear metal-thiosemicarbazone complexes. Pt (NT1Pt, NT2Pt) and Pd (NT1Pd-NT4Pd) complexes were obtained as monomers by heating the ligand and appropriate metallic precursor under reflux, while the Co (NT1Co-NT4Co) and $\mathrm{Cu}$
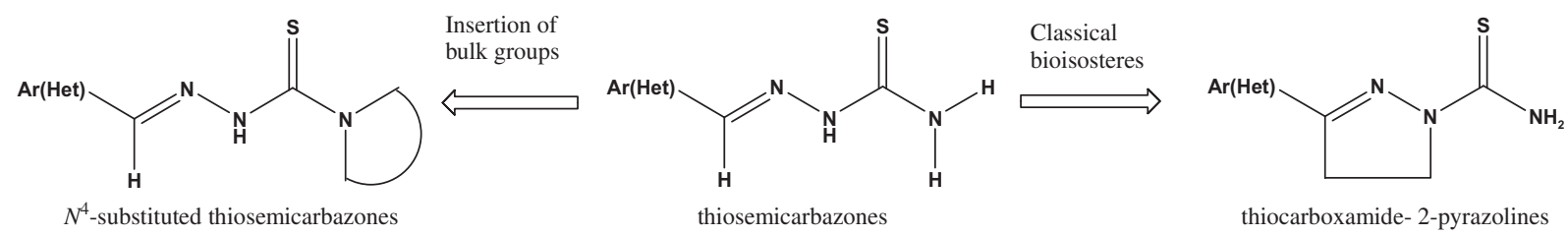

thiocarboxamide- 2-pyrazolines

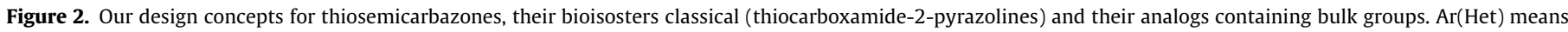
either aromatic or heterocyclic rings. 
(NT1Cu-NT4Cu) were obtained as bis-chelated complexes under similar conditions (Scheme 1). Elemental analysis data (C, H, N, and $\mathrm{Cl}$ ) confirmed this metal-ligand ratio and accorded well with the calculated values.

The IR spectral signatures of NT1-NT4 thiosemicarbazones show bands in the region at $1059-1109 \mathrm{~cm}^{-1}$ due to $(v \mathrm{C}=\mathrm{S})$, while no absorption appeared due to $(v \mathrm{C}-\mathrm{SH})$ in the region $2500-$ $2600 \mathrm{~cm}^{-1}$, suggesting that these NT1-NT4 remain in its thione tautomeric form. For the metal complexes, although no shift was observed in the vibrations attributed to $(v \mathrm{C}-\mathrm{O}-\mathrm{C})$ of furan ring, absorptions attributed to $(v \mathrm{C}=\mathrm{S})$ at $1059-1109 \mathrm{~cm}^{-1}$ were shifted to lower frequency $\left(12-30 \mathrm{~cm}^{-1}\right)$ after the metallic complexation, indicating that thionic sulfur does participate in the sphere of co-ordination. More notably, strong bands at $1576-1603 \mathrm{~cm}^{-1}$ were observed in all the complexes, which can be attributed to chelation of $(v \mathrm{C}=\mathrm{N})$ with the metal. ${ }^{19 \mathrm{a}, 26 \mathrm{~b}}$ By contrast, the $(v \mathrm{CH}=\mathrm{N})$ bands for the metal-free ligands are generally of higher frequency (1613-1615 $\mathrm{cm}^{-1}$ ) and are of weaker intensity than those observed in the metal complexes. Bands observed in the region of $3100 \mathrm{~cm}^{-1}(v \mathrm{~N}-\mathrm{H})$ were also slightly shifted in the complexes, probably by any kind of adjustment of current around the thioamide group. Taking into account previous assignments for similar metal-thiosemicarbazone complexes, bands corresponding to metal-to-ligand stretching modes were tentatively assigned. ${ }^{21}$ Thus, bands in the region of low wave-number (472-522 and 347$435 \mathrm{~cm}^{-1}$ ) were assigned to $v \mathrm{M}-\mathrm{N}$ and $v \mathrm{M}-\mathrm{S}$, respectively.

The ${ }^{1} \mathrm{H}$ NMR spectra of the ligands and their complexes were consistent with their corresponding protons both in terms of chemical shifts and the number of hydrogen atoms, in accordance with the proposed structure, allowing the assignment of each proton for the complexes. Regarding the ligands, it is worth reporting that even in DMSO- $d_{6}$ they were obtained in the thione form, which was confirmed by the absence of signal at ca. $4.0 \mathrm{ppm}$ (-SH proton). Regarding the metallic complexes, the $\mathrm{CH}=\mathrm{N}$ protons resonated at 6.6-7.3 ppm (singlet), owing to a deshielding effect observed for those protons that are in close proximity to the co-ordinating atoms (azomethine nitrogen), while, on free ligands, $\mathrm{CH}=\mathrm{N}$ protons resonated at 7.8-8.0 ppm. On the basis of these comparisons, we suggest that an $N, S$-bidentate co-ordination is involved in these complexes, as proposed in Scheme 1.

Attempts to obtain single crystals of these metallic complexes suitable for X-ray diffraction were unsuccessful. To overcome this, additional analyzes were recorded and carefully studied. The mass spectra of the ligands and their metal complexes have showed the expected fragment ions, confirming the respective molecular weights. The overall splitting pathways of selected metal complexes are summarized in Supplementary data (Scheme S1). According to the electronic spectra, the NT1-4 ligands exhibited three bands in the region at 220-207, 276-263, and 348-330 $\mathrm{nm}$. The most probable assignments for these bands are the $n \rightarrow \pi^{*}$ (thiosemicarbazone), $\pi \rightarrow \pi{ }^{*}$ (thiophene), and $\Phi \rightarrow \Phi^{*}$ (thiophene) transitions, respectively. A careful comparison of these bands with the electronic spectra of metallic complexes showed that there was an increase in intensity and a decrease in frequency due to the extended conjugation of ligands after the complexation. The observation of strong bands between 660 and $560 \mathrm{~nm}$ for the Pt (NT1Pt, NT2Pt) and Pd

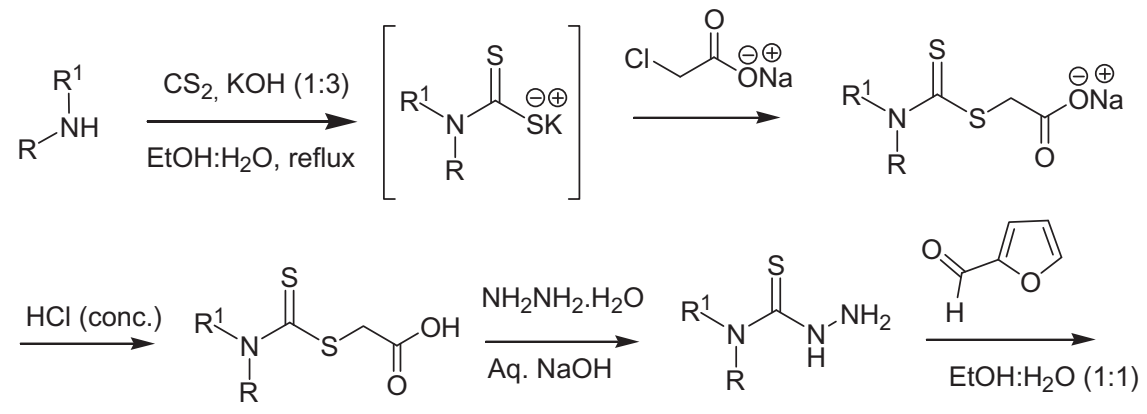

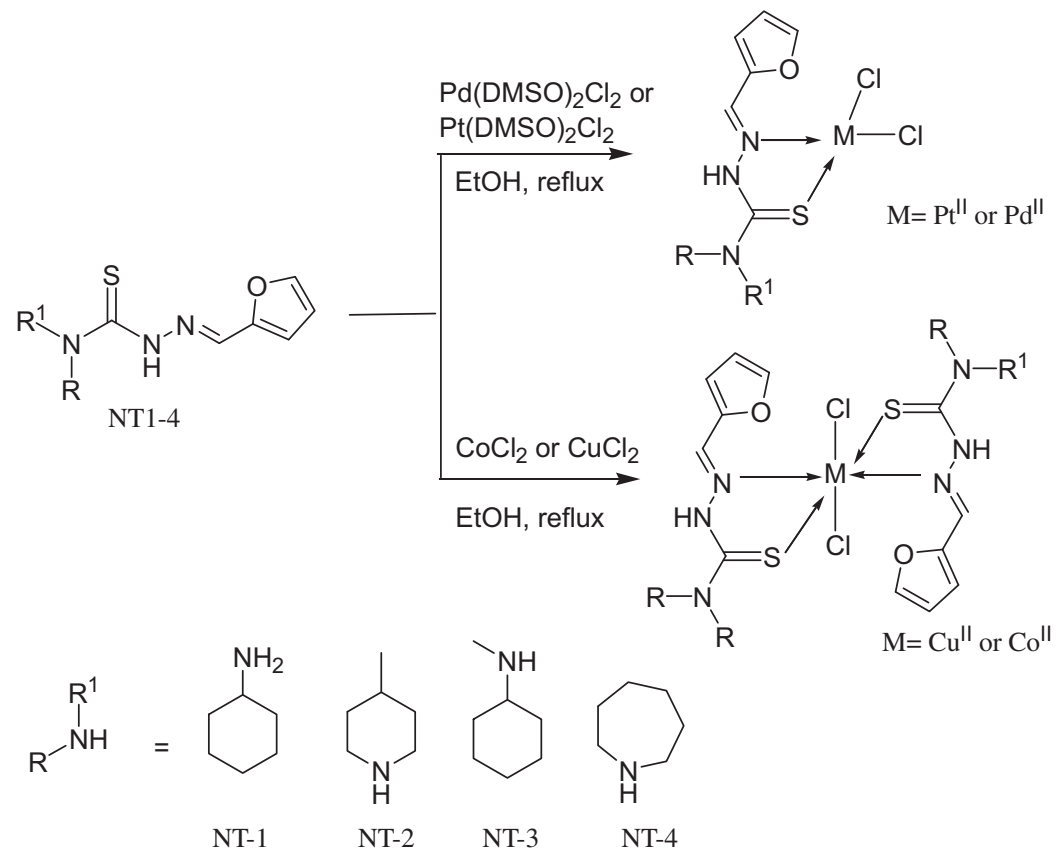

Scheme 1. Preparation of ligands (NT1-4) and their metal complexes. 
(NT1Pd-NT4Pd) complexes were assigned to ${ }^{1} A_{1} g \rightarrow 1 A_{2 g}$ that are typically of a square planar geometry. For these complexes, the ground state is ${ }^{1} \mathrm{~A}_{1} \mathrm{~g}$ and the excited states are ${ }^{1} \mathrm{~A}_{2} \mathrm{~g},{ }^{1} \mathrm{~B}_{1} \mathrm{~g}$, and ${ }^{1} \mathrm{Eg}$ in order of increasing energy. Intense bands were also observed at $433-470 \mathrm{~nm}$ and assignable to a combination of $\mathrm{S} \rightarrow \mathrm{Pd}^{\|}$and ${ }^{1} \mathrm{~A}_{1 \mathrm{~g}} \rightarrow{ }^{1} \mathrm{~B}_{1 \mathrm{~g}}$ transitions. ${ }^{27}$ The Pt (NT1Pt, NT2Pt) and Pd (NT1PdNT4Pd) complexes were diamagnetic, as expected for a kind of complex that assumes the planar geometry.

For the Co (NT1Co-NT4Co) and Cu (NT1Cu-NT4Cu), two-spin was observed to allowed transitions at $575-550 \mathrm{~nm}$ and at $475-$ $450 \mathrm{~nm}$ and attributed to ${ }^{4} \mathrm{~T}_{1 \mathrm{~g}}(\mathrm{~F}) \rightarrow{ }^{4} \mathrm{~T}_{2 \mathrm{~g}}(\mathrm{~F})\left(v_{1}\right)$ and ${ }^{4} \mathrm{~T}_{1 \mathrm{~g}}(\mathrm{~F}) \rightarrow 4 \mathrm{~T}_{1 \mathrm{~g}}(\mathrm{P})$ $\left(v_{3}\right)$. These transitions are suggestive of an octahedral geometry. Likewise, the ${ }^{2} \mathrm{E}_{\mathrm{g}}$ and ${ }^{2} \mathrm{~T}_{2 \mathrm{~g}}$ microstates of the octahedral $\mathrm{Cu}^{\| l}$ ion (of configuration $\mathrm{d}^{9}$ ) split under the influence of the tetragonal distortion and such distortion causes the transitions ${ }^{2} \mathrm{~B}_{1 \mathrm{~g}} \rightarrow{ }^{2} \mathrm{~B}_{2 \mathrm{~g}}$ and ${ }^{2} \mathrm{~B}_{1 \mathrm{~g}} \rightarrow{ }^{2} \mathrm{~A}_{1 \mathrm{~g}}$, although this remains unresolved in the electronic spectra. ${ }^{28}$ These transitions lie within the single broad envelope centered on the range mentioned above. But these assignments accorded well with the general observation that transitions of the $\mathrm{Cu}^{\|}$ $\mathrm{d}-\mathrm{d}$ kind are often very similar in terms of energy. ${ }^{29} \mathrm{The} \mathrm{N}-\mathrm{Cu}^{\| l}$ and $\mathrm{S}-\mathrm{Cu}$ ll ligand-to-metal charge transfer transitions were also observed at $460 \mathrm{~nm}$ (Table S1, supplementary data). The $\mathrm{Cu}$ and $\mathrm{Co}$ complexes exhibited room temperature magnetic moments $\left(\mu_{\text {eff }}\right)$ values in the range of $1.92-1.97$ and 5.05-5.12 B.M., respectively (Table 1). These values are expected for magnetically diluted $\mathrm{Cu}^{\|}$ and $\mathrm{Co} \|$ complexes having unpaired electrons in the d-orbital. ${ }^{30}$

The EPR spectra of the $\mathrm{Cu}^{\|}$and $\mathrm{Co}^{\|}$complexes were measured and the parameters are summed in Table 1. The general trend $g_{\|}>g_{\perp}>2.0$ for the $\mathrm{Cu}$ complexes suggests that the unpaired electron is located on the $\mathrm{d}\left(x^{2}-y^{2}\right)$ ground state orbitals on the $\mathrm{Cu}^{\| 31}$ and can also be taken as evidence of an octahedral environment. ${ }^{32}$ Likewise, the Co complexes exhibiting the $g$ value between 2.05 and 2.08, which also suggests an octahedral environment around the metal. ${ }^{33}$ To sum up, a square planar geometry is suggested for both the Pt ${ }^{\|}$(NT1Pt, NT2Pt) and Pd" (NT1Pd-NT4Pd) complexes, while $\mathrm{Cu}^{\|}$complexes (NT1Cu-NT4Cu) and $\mathrm{Co}^{\|}$complexes (NT1Co-NT4Co) probably are of octahedral geometry.

These complexes are insoluble in water, sparingly soluble in methanol and ethanol, but soluble in DMF and DMSO, producing intense reddish, greenish or brownish solutions. The ${ }^{1} \mathrm{H}$ NMR spectra of metal complexes in DMSO- $d_{6}$ remained unchanged at room temperature for several days, showing no evidence of displacement of the thiosemicarbazones by the solvent. The solid-state geometry of dichloropalladium (NT1Pd-NT4Pd) and dichloroplat- inum (NT1Pt, NT2Pt) complexes is not retained in DMSO solution, taking place an fast transformation of $\left[\mathrm{MLCl}_{2}\right]$ to [ML(DMSO)Cl] complexes. All complexes were suspended in DMSO, thereby the biological activity reflects the presence of (DMSO)chlorometal complexes for the Pt and Pd ones. ${ }^{34}$

\subsection{Pharmacological and physicochemical assays}

All the ligands and complexes were tested against the erythrocytic stage (bloodstream form of clinical relevance) of $P$. falciparum (W2 clone, Chloroquine-resistant and Mefloquine-sensitive), HM1:IMSS strain of $E$. histolytica trophozoites and also for cytotoxicity using BALB/c mouse splenocytes. The antiprotozoal properties were expressed in terms of the $\mathrm{IC}_{50}(\mu \mathrm{M})$ values, the cytotoxicity being expressed as the highest concentration tested that was non-cytotoxic for the splenocytes (Table 2). Mefloquine (MQF) and Metronidazole (MNZ) were used as reference drugs.

Recently, Sanchez-Delgado and co-workers have disclosed a number of correlations between physicochemical parameters and the antiplasmodium activity for a number of ruthenium-chloroquine complexes. ${ }^{17 c, 35}$ From these studies, important insights into the antiplasmodium action mechanism were provided. Therefore, the saline $/ n$-octanol partition coefficient $(\log P)$, studies with the pBR 322 plasmid DNA, and the inhibitory effects on the $\beta$-hematin formation for our most potent antiplasmodium metal-thiosemicarbazone complexes were also recorded (Table 3, Figs. 3 and 4).

\subsection{Structure-activity relationships (SAR)}

The first analysis of the pharmacological results showed that the NT1-4 ligands were only weak $P$. falciparum inhibitors. Likewise, they were only modestly active against $E$. histolytica, the most potent being NT2, which is still four times less potent than MNZ. Although it was not possible to draw SAR data from these results, they displayed generally low cytotoxicity against mammalian cells, which suggests an attractive application for the building of metallic complexes.

As $\mathrm{Cu}$ complexes (NT1Cu-NT4Cu) are isoelectronic and isostructural with the Co complexes (NT1Co-NT4Co), while a square planar geometry is adopted by both Pt (NT1Pt, NT2Pt) and Pd (NT1Pd-NT4Pd) complexes, we concluded that the most appropriate discussion of the biological results is through the comparison between the similar metals, along the comparative analysis of the complex and the respective metal-free ligand.

Table 1

Analytical and physical data for the metal complexes

\begin{tabular}{|c|c|c|c|c|c|c|c|}
\hline \multirow[t]{2}{*}{ Compd } & \multirow[t]{2}{*}{ Color } & \multirow[t]{2}{*}{ Yield $^{\mathrm{a}}(\%)$} & \multirow[t]{2}{*}{$\operatorname{Mp}\left({ }^{\circ} \mathrm{C}\right)$} & \multirow[t]{2}{*}{$\left(\mu_{\text {eff }}\right)^{b}$} & \multicolumn{3}{|c|}{ EPR parameters ${ }^{\mathrm{c}}$} \\
\hline & & & & & $g_{\|}$ & $g_{\perp}$ & $g$ \\
\hline NT1Pt & Yellowish solid & 34 & 260 & 0 & - & - & - \\
\hline NT2Pt & Pale yellow & 43 & 200 & 0 & - & - & - \\
\hline NT1Pd & Pale orange & 56 & 268 & 0 & - & - & - \\
\hline NT2Pd & Brick red & 30 & 257 & 0 & - & - & - \\
\hline NT3Pd & Pale yellow & 30 & 260 & 0 & - & - & - \\
\hline NT4Pd & Pale orange & 55 & 220 & 0 & - & - & - \\
\hline NT1Co & Brownish solid & 42 & 262 & 5.10 & - & - & 2.08 \\
\hline NT2Co & Wine red & 35 & $165-170$ & 5.05 & - & - & 2.05 \\
\hline NT3Co & Wine red & 33 & 265 & 5.12 & - & - & 2.05 \\
\hline NT4Co & Chocolate brown & 45 & 240 & 5.07 & - & - & 2.06 \\
\hline NT1Cu & Greenish solid & 54 & 158 & 1.92 & 2.30 & 2.07 & - \\
\hline NT2Cu & Pale green & 51 & 154 & 1.97 & 2.28 & 2.05 & - \\
\hline NT3Cu & Greenish solid & 32 & 160 & 1.92 & 2.10 & 2.05 & - \\
\hline NT4Cu & Pale orange & 40 & 164 & 1.95 & 2.20 & 2.06 & - \\
\hline
\end{tabular}

\footnotetext{
a Isolated products.

b Effective magnetic moment expressed as Bohr Magneton (B.M.) and recorded at room temperature.

c From frozen solutions (77 K) in DMSO.
} 
Table 2

Biological results of ligands and their metal complexes

\begin{tabular}{|c|c|c|c|}
\hline Compd complexes & $\begin{array}{l}\text { P. falciparum W2 strain } \\
\mathrm{IC}_{50}(\mu \mathrm{M}) \text { after } 24 \mathrm{~h}^{\mathrm{a}}\end{array}$ & $\begin{array}{l}\text { E. histolytica HM- } 1 \text { :IMSS strain } \\
\mathrm{IC}_{50}(\mu \mathrm{M}) \text { after } 72 \mathrm{~h}^{\mathrm{a}}\end{array}$ & $\begin{array}{l}\text { Cytotoxicity to mammalian } \\
\text { cells }\left(\mu \mathrm{g} \mathrm{mL}^{-1}\right)^{\mathrm{b}}\end{array}$ \\
\hline NT1 & $20.3 \pm 0.2$ & $10.12 \pm 00.5$ & 33 \\
\hline NT2 & $36.2 \pm 0.06$ & $8.02 \pm 00.1$ & 100 \\
\hline NT3 & $21.8 \pm 0.4$ & $9.07 \pm 00.4$ & $>100$ \\
\hline NT4 & $35.8 \pm 0.9$ & $12.08 \pm 00.3$ & $>100$ \\
\hline NT1Pt & $37.0 \pm 0.1$ & $3.47 \pm 00.1$ & 33 \\
\hline NT2Pt & $42.3 \pm 0.6$ & $1.44 \pm 00.3$ & $>100$ \\
\hline NT1Pd & $10.0 \pm 0.08$ & $0.99 \pm 00.3$ & $3.3(7.7)$ \\
\hline NT2Pd & $10.9 \pm 0.1$ & $0.6 \pm 00.5$ & 33 \\
\hline NT3Pd & $18.3 \pm 0.3$ & $2.42 \pm 00.5$ & 33 \\
\hline NT4Pd & $20.5 \pm 0.01$ & $1.66 \pm 00.1$ & 33 \\
\hline NT1Co & $\mathrm{Nd}$ & $2.28 \pm 00.1$ & 33 \\
\hline NT2Co & $41.0 \pm 0.4$ & $3.40 \pm 00.2$ & 33 \\
\hline NT3Co & $21.4 \pm 0.2$ & $7.50 \pm 00.5$ & 33 \\
\hline NT4Co & $58.7 \pm 1.7$ & $2.00 \pm 00.3$ & 100 \\
\hline NT1Cu & $4.6 \pm 0.1$ & $1.11 \pm 00.2$ & 33 \\
\hline NT2Cu & $5.2 \pm 0.1$ & $4.05 \pm 00.1$ & 11 \\
\hline NT3Cu & $7.8 \pm 2.0$ & $1.80 \pm 00.2$ & 33 \\
\hline NT4Cu & $4.6 \pm 0.1$ & $1.06 \pm 00.4$ & $3.3(5.1)$ \\
\hline $\mathbf{M Q N}^{\mathrm{c}}$ & $0.039 \pm 0.01$ & - & N.d. \\
\hline $\mathbf{M N Z}^{\mathrm{c}}$ & - & $1.80 \pm 00.3$ & N.d. \\
\hline
\end{tabular}

N.d., not determined at concentrations tested.

a Calculated from five concentrations using data obtained from at least three independent experiments. Values are mean \pm standard deviation of three determinations.

b Expressed as the highest non-cytotoxic concentration for BALB/c mouse splenocytes. Values given in parentheses are expressed in $\mu \mathrm{M}$.

c MQN is Mefloquine and MNZ is Metronidazole.

Table 3

Inhibitory effects on the $\beta$-hematin formation and partition coefficient $(\log P)$ for the copper complexes

\begin{tabular}{lcl}
\hline Compd complexes & $\mathrm{IC}_{50}\left(\mu \mathrm{g} \mathrm{mL}^{-1}\right)^{\mathrm{a}}$ & $\log P^{\mathrm{b}}$ \\
\hline NT1Cu & $>50$ & -1.73 \\
NT2Cu & 48 & -1.54 \\
NT3Cu & 43 & -1.49 \\
NT4Cu & $>50$ & -0.89 \\
CP $^{\mathrm{c}}$ & 1.3 & - \\
\hline
\end{tabular}

a Calculated from six concentrations using data obtained from two independent experiments. Values mean \pm 1.0

b Performed as described in Section 4.

c $\mathrm{CP}$ is chloroquine diphosphate.

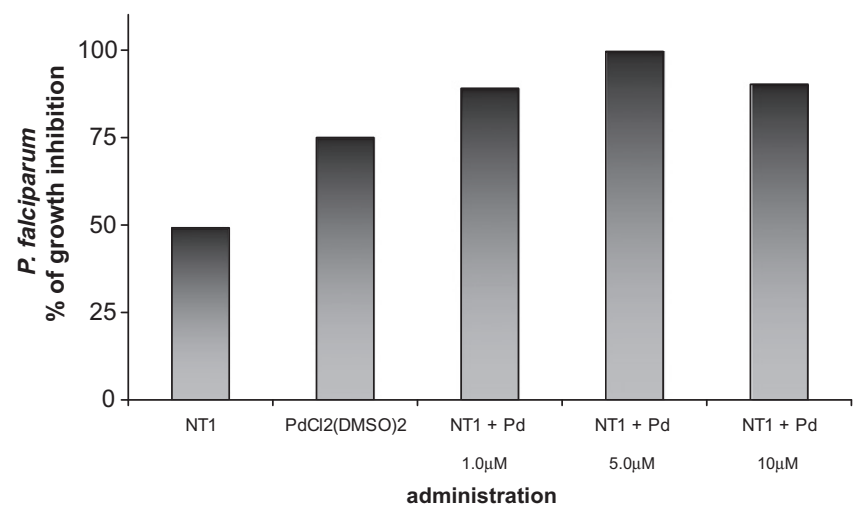

Figure 3. In vitro inhibition of $P$. falciparum growth at alone or concomitant addition of ligand (NT1) plus metal $\left[\mathrm{PdCl}_{2}(\mathrm{DMSO})_{2}\right.$, represented as Pd]. NT1 was added at fix concentration of $20 \mu \mathrm{M}$, while Pd was used at $10 \mu \mathrm{M}$ (alone) or at increasing concentrations (in concomitant with NT1). Data were measured in triplicate after $24 \mathrm{~h}$ of incubation, and the percentages of inhibitions were established in comparison to non-treated cells (control).

We first analyzed the Pt and Pd series. Although the investigation of Pt complexes was limited by synthetic considerations and only two complexes (NT1Pt and NT2Pt) were prepared, these

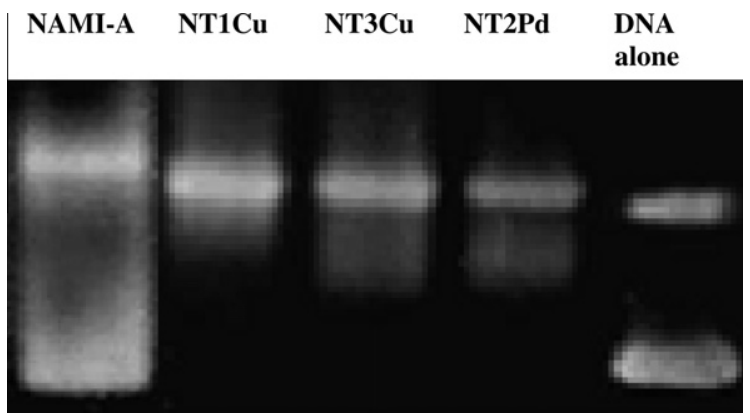

Figure 4. Effect of complexes NAMI-A, NT1Cu, NT3Cu, and NT2Pd (50 $\mu \mathrm{M})$ on the mobility of pBR 322 plasmid DNA. DNA was incubated in $20 \mu \mathrm{M}$ phosphate buffer $(\mathrm{pH} 7.5)$ to a final volume of $20 \mu \mathrm{L}$, and incubated in the absence or presence of tested complexes at $37^{\circ} \mathrm{C}$ in the dark for $24 \mathrm{~h}$.

showed near $\mathrm{IC}_{50}$ values against $P$. falciparum. On the one hand, the Pt complexes showed improved potency against $P$. falciparum compared with than the metal-free ligands (NT1 and NT2). On the other hand, the replacement of Pt by Pd led to only a slight increase in potency against $P$. falciparum ( IC $_{50}$ of $10.0-20.5 \mu \mathrm{M}$ ), far lower than the potency of MQN, which is active in nanomolar concentrations. Apart from NT1Pd, which was cytotoxic at low doses, the other Pt and Pd complexes retained their low cytotoxicity in mammalian cells. Noticeably, most of Pt and Pd complexes were highly potent in inhibiting the growth of $E$. histolytica, exhibiting the same range of potency as the reference drug, MNZ. A comparison of the inhibitory activity of ligand NT2 and the NT2Pd complex, the latter proved to be 13 times more potent in inhibiting the proliferation of E. histolytica. By contrast, the replacement of ligand NT2 by NT3 resulted in the NT3Pd complex, which was only three times more potent than the free-ligand in inhibiting the growth of E. histolytica.

Regarding the antiplasmodial activity, the screening of Co and $\mathrm{Cu}$ complexes demonstrated more promising results than the $\mathrm{Pt}$ and $\mathrm{Pd}$ complexes. Analysis of these $\mathrm{Co}$ and $\mathrm{Cu}$ complexes bearing two molecules of ligands gave rise to interesting SAR observations. The complexation of NT1-4 ligands with Co led a new set of 
complexes that were (at least) one order of magnitude less active against $P$. falciparum (or in some cases virtually inactive, e.g., for NT1Co and NT4Co) when compared with the metal-free ligands. Conversely, the complexation with Co resulted in antiamoebic complexes more potent than the corresponding metal-free ligands.

Regarding the metal-free thiosemicarbazones (IC 50 of 20.3$36.2 \mu \mathrm{M}$ ), their $\mathrm{Cu}$ complexes were proven to be good antiplasmodial agents ( IC $_{50}$ of $4.6-7.8 \mu \mathrm{M}$ ), exhibiting the following order of potency: $\mathbf{N T 1 C u}=\mathbf{N T 4 C u}>\mathbf{N T 2 C u}>\mathbf{N T 3 C u}$. Altering the structure of the cyclohexyl ring on the ligands of C-methyl (NT2Cu) to $\mathrm{N}$ methyl (NT3Cu) led to a slight reduction in potency $\left(\mathrm{IC}_{50}=5.2 \mathrm{vs}\right.$ $7.8 \mu \mathrm{M}$ ). Moreover, it was observed that, although the ring expansion of cyclohexyl (NT1Cu) by cycloheptane (NT4Cu) retains the antiplasmodial activity, NT4Cu was cytotoxic against mammalian cells.

\subsection{Advanced biological experiments}

On the basis of the SAR data presented in Table 2, it seems that the antiplasmodial activity of these complexes is dependent on the substituents (R) on the structures of thiosemicarbazones (NT1-4). In general, the lipophilicity of metallic structures is a relevant descriptor for explaining the cell uptake, and for explaining the difference in potency between the metal complex and its metal-free ligand. In the case of anti-malarial complexes, such as Ferroquine $^{16 \mathrm{~d}}$ and ruthenium-chloroquine, ${ }^{17 c, 35}$ the antiplasmodium activity is governed by the influence of lipophilicity. The lipophilicity $(\log P)$ of our most potent antiplasmodium complexes (NT1Cu-NT4Cu) was thus measured, in order to check any kind of correlation with the biological activity. Comparing the experimental values of $\log P$ (Table 3 ) with the $\mathrm{IC}_{50}$ values against the W2 strain $P$. falciparum, a correlation between the potency and lipophilicity is not observed. However, comparing the lipophilicity of NT1 $(\log P=2.16)$ ligand and its copper complex (NT1Cu), it is possible to conclude that the copper complexes are in fact more hydrophilic than the free thiosemicarbazones.

To ascertain whether complexation with a ligand is an essential factor for antiprotozoal activity, the same culture of W2 strain $P$. falciparum was simultaneously treated with stoichiometric quantities $(20 \mu \mathrm{M})$ of metal-free ligand NT1 and its metallic precursor $\left[\mathrm{PdCl}_{2}(\mathrm{DMSO})_{2}\right]$, with the percentage of cell growth inhibition being measured after $24 \mathrm{~h}$ of treatment. In this condition, only $56 \%$ of the $P$. falciparum proliferation was inhibited, approximately twice lower than that of the corresponding PdNT1 complex (98\% of inhibition at $20 \mu \mathrm{M}$ ). Since the bioactivity of simultaneously treatment (ligand plus metallic precursor) and its corresponding metallic complex are distinct, the antiplasmodium activity of these complexes is not governed by synergistic effects alone. Cumulatively, it is supposed that the formation of a metal complex, rather than the simple presence of the ligand or transition metal alone, plays a crucial role in determining its antiprotozoal properties.

Regarding the lability of thiosemicarbazones, Bernhardt and coworkers have proposed that thiosemicarbazones from metallic complexes are displaced (dissociated) under physiological conditions or, in other words, the metals act as lipophilic vehicles, facilitating the intracellular delivery of the metal-free thiosemicarbazones into cellular compartments. ${ }^{19 b, c}$ In light of these findings, it is supposed that the processes of precomplexation and dissociation play a pivotal role in determining the pharmacological potency for the metallic complexes described here. To gather additional evidences, additional biological assays were performed with palladium, which is kinetically more labile than $\mathrm{Cu}, \mathrm{Co}$, or Pt.

The same culture of W2 strain P. falciparum was simultaneously treated with metal-free ligand NT1 $(20 \mu \mathrm{M})$ and its metallic precursor $\left[\mathrm{PdCl}_{2}(\mathrm{DMSO})_{2}\right]$ at increasing concentrations (1.0, 5.0, and $10 \mu \mathrm{M})$, with the percentage of cell growth inhibition being mea- sured after $24 \mathrm{~h}$ of treatment. From the data on Figure 3, it is possible to suggest that the increasing addition of Pd enhances the antiplasmodium activity of NT1 ligand at certain point. However, at high concentrations of $\mathrm{Pd}$ (more than $10 \mu \mathrm{M}$ ), no differences of inhibitions are observed, may because of metal toxicity (data not shown). Although preliminary, the role of metal facilitating the intracellular delivery of thiosemicarbazones into cellular compartments may occur in the complexes described here, providing a means for drug activation or formation of reactive species that could eventually interact with the protozoan targets.

As previously cited, there are various examples of drug targets of P. falciparum. Following the findings provided by Sanchez-Delgado and co-workers, the DNA and hematin were considered as potential drug targets. ${ }^{35}$ Therefore, studies of DNA interaction in cell-free media was conducted, employing pBR 322 plasmid DNA (composed of the supercoiled form of higher mobility and an open circular relaxed form) and CT-DNA (denatured form). We chose three of the most potent and non-cytotoxic complexes to be tested, NT1Cu, NT3Cu, and NT2Pd. These complexes are insoluble in pure water, and DMSO was thus used as a co-solvent in concentrations that do not affect the CT-DNA. The addition of the metal complexes to the CT-DNA solution resulted in small changes in the UV-vis absorption spectra. The observed changes were almost identical in the presence of each of these three complexes, suggesting that the complexes interact with CT-DNA in the same way (data not shown).

More valuable informations were gathered by way of agarose gel electrophoresis assays using pBR 322 plasmid DNA. In this assay, the NAMI-A (an imidazole-ruthenium ${ }^{\|}$complex, Fig. 1) of recognized in vitro antiplasmodium property ${ }^{17}$ e was used, so as to establish a point of reference for the metal entity. At concentrations below $50 \mu \mathrm{M}$, the complexes (NT1Cu, NT3Cu, and NT2Pd) did not alter either the migration of plasmid DNA bands or other interaction processes (cleavage, for instance) to a significant degree, while the NAMI-A showed interactions as soon as a concentration of $10 \mu \mathrm{M}$ was reached. However, at $50 \mu \mathrm{M}$, a new pattern was observed after the incubation of these complexes with plasmid DNA. Figure 4 suggests that the DNA interaction of these complexes occurs through the conversion of the supercoiled form, probably to the relaxed form, while the NAMI-A-treated DNA behaved quite differently, exploiting the cleavage process.

Inhibition of $\beta$-hematin formation was also measured for our more potent copper complexes (Table 3 ). All the tested complexes did not inhibit the $\beta$-hematin formation to a significant extent, while chloroquine did. This suggests these complexes use a different action mechanism than quinoline-based antimalarial drugs. In view of the current problem of resistance to anti-malarial drugs, ${ }^{3}$ it is especially important to identify novel anti-malarial drug candidates not based on quinolines.

As a result of these assays, the plasmodicidal action mechanism must, in part, be related to action on the DNA structure. As for the antiamoebic properties of these metal complexes, it is not clear whether the antiamoebic action mechanism involves their interaction with DNA. Although additional experimental data is not available at present, a very recent survey of the literature indicates that the sequestration of Fe via either chelator compounds or exchange of endogenous Fe by exogenous metal (transmetalation) affects E. histolytica viability. ${ }^{36}$ In light of these studies, it is reasonable to propose that, given the recognized ability of thiosemicarbazones to act as Fe chelators, as well as the feasibility of the complexes described here to participate in the processes of dissociation, they may use this action mechanism to inhibit the growth of E. histolytica.

\section{Conclusions}

We were able to identify NT2Pd as the most potent antiamoebic agent tested in this study, being twice as effective as MNZ. NT2Pd 
did not show cytotoxicity against splenocytes at a concentration 10 times higher than that capable of inhibiting E. histolytica growth. In other words, it was effective at concentrations that do not overtly affect mammalian cells. This represents the kind of profile, that is, generally required for antiparasitic agents, with selective toxicity against parasites, although future investigations in animal models are necessary.

Our most potent antiplasmodial complex, NT1Cu, is far less potent than MNQ. However, the copper complexes, particularly NT1Cu and NT2Cu, represent good starting points for further medicinal chemistry programs aiming to discover antimalarial drug candidates based on metallic structures. Our future goals are to study $\mathrm{Pd}$ and $\mathrm{Cu}$ complexes bearing mixed-ligands to further validate the hypothesis that the process of dissociation may occur and could be exploited to produce complexes more active complexes against the aforementioned parasites.

\section{Experimental section}

\subsection{Chemistry}

General remarks: reactions were monitored by TLC analysis using Merck pre-coated aluminum plate silica gel $60 \mathrm{~F}_{254}$ thin layer plates. All the chemicals were purchased from Aldrich Chemical Company (USA). Elemental analysis (C, H, N) was carried out by Central Drug Research Institute, Lucknow (India). Chlorine was estimated by decomposing the complexes with $\mathrm{Na}_{2} \mathrm{O}_{2} / \mathrm{NaOH}$ and precipitating as $\mathrm{AgCl}$ with $\mathrm{AgNO}_{3}$ after dissolving in diluted $\mathrm{HNO}_{3}$. Melting points were recorded on KSW melting point apparatus and are uncorrected. Electronic spectra were recorded in methanol on a Shimadzu UV-1601 PC UV-visible spectrophotometer. IR spectra on $\mathrm{KBr}$ disks were recorded on a Perkin Elmer model 1620 FT-IR spectrophotometer. ${ }^{1} \mathrm{H}$ NMR spectra were obtained at ambient temperature using a Brucker spectroscopin DPX$300 \mathrm{MHz}$ spectrophotometer in DMSO- $d_{6}$ using TMS as an internal standard. Splitting patterns are designated as follows: s, singlet, d, doublet, $\mathrm{m}$, multiplet. The FAB mass spectra of all the complexes were recorded on a JEOL SX 102/DA-6000 Mass Spectroscopy/Data System, using argon/xenon $(6 \mathrm{kV}, 10 \mathrm{~mA})$ as the $F A B$ gas and $m$-nitrobenzyl alcohol (NBA) as the matrix. Room temperature magnetic susceptibility was measured at $298 \mathrm{~K}$ by a Vibrating sample Magnetometer 155, E-112 ESR Spectrometer, Varian, USA using nickel as standard and such values were expressed as effective magnetic moment $\left(\mu_{\text {eff }}\right)$ in Bohr Magneton (B.M.). The electron paramagnetic resonance (EPR) spectra were recorded with a Bruker ESP 300E X-band spectrometer.

\subsubsection{Synthesis of ligands}

The thioglycolic acids were prepared as outlined in reference. ${ }^{37}$ The thiosemicarbazones were synthesized by heating at reflux an aqueous solution of respective aminothiocarbonylhydrazines $(0.003 \mathrm{~mol}$ in $10 \mathrm{~mL})$ with ethanolic solution of furan-2-carboxaldehyde $(0.228 \mathrm{~g}, 0.003 \mathrm{~mol}$ in $10 \mathrm{~mL}$ ) for $3 \mathrm{~h}$ with continuous stirring. After cooling, the precipitated compound was filtered and recrystallized from appropriate solvent.

\subsubsection{Synthesis of $\mathrm{Pd}^{\|}$and $\mathrm{Pt}^{\|}$complexes of thiosemicarbazones}

The synthesis of $\mathrm{Pd}^{\|}$and $\mathrm{Pt}^{\|}$complexes [M(DMSO $)_{2} \mathrm{Cl}_{2}$, where $\mathrm{M}$ is Pd or Pt] were prepared in accordance the procedure outlined in the literature. ${ }^{38} \mathrm{~A}$ solution of $\left[\mathrm{Pd}(\mathrm{DMSO})_{2} \mathrm{Cl}_{2}\right] /\left[\mathrm{Pt}(\mathrm{DMSO})_{2} \mathrm{Cl}_{2}\right]$ $(2 \mathrm{mmol})$ dissolved in methanol $(5 \mathrm{~mL})$ was added to a solution of respective ligand ( $2 \mathrm{mmol}$ ) previously dissolved in a minimum quantity of methanol and the reaction mixture was heated under reflux for $1-3 \mathrm{~h}$. After keeping the solution at $0{ }^{\circ} \mathrm{C}$ overnight, the colored solid was filtered out. This was washed with hot water fol- lowed by a small quantity of methanol and dried in a vacuum desiccator over anhydrous silica gel to give amorphous solids.

\subsubsection{Synthesis of $\mathrm{Cu}^{\|}$and $\mathrm{Co} \|$ complexes of thiosemicarbazones}

A stirred solution of hydrated metal chloride $(2 \mathrm{mmol})$ dissolved in minimal quantity of methanol was added to a stirring hot solution of ligand $(4 \mathrm{mmol})$ in methanol $(20 \mathrm{~mL})$ and the reaction mixture was heated under reflux for $1-3 \mathrm{~h}$. This solution was kept to room temperature overnight, when the precipitate was filtered out, washed with hot water followed by small quantity of methanol, and dried. Recrystallization was carried out from methanol.

\subsection{Pharmacological procedures}

\subsubsection{Cytotoxicity to mammalian cells}

The cytotoxicity of the compounds and metal complexes was determined using BALB $/ \mathrm{c}$ mouse splenocytes $\left(5 \times 10^{6}\right.$ cells well ${ }^{-1}$ ) cultured in 96-well plates in Dulbecco's Modified Eagle's Medium (DMEM, Sigma Chemical Co., St. Louis, MO) supplemented with $10 \%$ of fetal calf serum (FCS; Cultilab, Campinas, SP, Brazil) and $50 \mu \mathrm{g} \mathrm{mL}^{-1}$ of gentamycin (Novafarma, Anápolis, GO, Brazil). Each compound was evaluated in five concentrations $(1.1,3.3$, 11,33 , and $100 \mu \mathrm{g} \mathrm{m}^{-1}$ ), in triplicate. Cultures were incubated in the presence of ${ }^{3} \mathrm{H}$-thymidine $\left(1 \mu \mathrm{Ci}\right.$ well $\left.{ }^{-1}\right)$ for $24 \mathrm{~h}$ at $37^{\circ} \mathrm{C}$ and $5 \% \mathrm{CO}_{2}$. After this period, the content of the plate was harvested to determine the ${ }^{3} \mathrm{H}$-thymidine incorporation using a $\beta$-radiation counter (Multilabel Reader, Hidex, Turku, Finland). The cytotoxicity of the compounds was determined comparing the percentage of ${ }^{3} \mathrm{H}$-thymidine incorporation (as indicator of viability cell) of drug-treated wells in relation to untreated wells. Non-cytotoxic concentrations were defined as those causing a reduction of ${ }^{3} \mathrm{H}$-thymidine incorporation below $10 \%$ in relation to untreated controls. Note: BALB/c mice were handled according to the NIH guidelines for animal experimentation. All procedures described here had prior approval from the animal ethics committee of FIOCRUZ (Brazil).

\subsubsection{Antimalarial activity}

It was performed using the $\left[{ }^{3} \mathrm{H}\right]$-hypoxanthine incorporation assay, as previously described. ${ }^{39}$ Briefly, parasites were maintained in continuous culture of human erythrocytes (blood group $\mathrm{O}^{+}$) using RPMI 1640 medium supplemented with $10 \%$ human plasma. Parasites grown at $1-2 \%$ parasitemia and $2.5 \%$ hematocrit were incubated with the pure substances tested at five different concentrations, diluted with 4\% DMSO in culture medium (RPMI 1640) without hypoxanthine. Cultures containing parasites were harvested using a cell harvester to evaluate the $\left[{ }^{3} \mathrm{H}\right]$-hypoxanthine incorporation in a $\beta$-radiation counter. Inhibition of parasite growth was evaluated by comparison with $\left[{ }^{3} \mathrm{H}\right]$-hypoxanthine uptake in drug treated versus untreated wells after $24 \mathrm{~h}$ of incubation with the tested compounds. $\mathrm{IC}_{50}$ values were calculated triplicates, comparing with the Mefloquine (MQN) as standard drug.

\subsubsection{Antiamoebic activity}

Thiosemicarbazones and their metal complexes were screened against the HM-1:IMSS strain of E. histolytica by using the microplate method. ${ }^{40}$ All the experiments were carried out in triplicates at each concentration level and repeated thrice. E. histolytica trophozoites were cultured in TYI-S-33 growth medium in wells of 96 well microtiter plates. ${ }^{41}$ DMSO $(40 \mu \mathrm{L})$ was added to all the samples ( $1 \mathrm{mg}$ ) followed by enough culture medium to obtain concentration of $1 \mathrm{mg} / \mathrm{mL}$. The maximum concentration of DMSO in the test did not exceeded $0.1 \%$, and at this level no inhibition of amoebal growth has occurred. Compounds were further diluted with medium to a concentration of $0.1 \mathrm{mg} \mathrm{mL}^{-1}$. Twofold serial 
dilutions were made in the wells of 96-well microtiter plate. Each test included Metronidazole (MNZ) as the standard amoebicidal drug, control (culture medium plus parasite) and a blank (culture medium only). The cell suspension was then diluted to $10^{5}$ organism/mL by adding fresh medium and $170 \mu \mathrm{L}$ of this suspension was added to the test and control well in the plate. Plate was sealed and gassed for $10 \mathrm{~min}$ with nitrogen before incubation at $37^{\circ} \mathrm{C}$ for $72 \mathrm{~h}$. After incubation, the growth of amoebae in the plate was checked with a low power microscope and the optical density of the solution in each well was determined at $490 \mathrm{~nm}$ with a microplate reader. The\% inhibition of amoebal growth was calculated from the optical densities of the control and test wells and plotted against the logarithm of the dose of the drug tested. Linear regression analysis was used to determine the best-fitted straight line from which the $\mathrm{IC}_{50}$ value was found.

\section{Acknowledgements}

This study received support from Council of Scientific and Industrial Research (grant \#01(2278)/08/EMR-II New Delhi, India), Pernambuco State Foundation of Science (FACEPE, grant \#APQ0123-4.03/08, Brazil), and Bahia State Foundation of Science (FAPESB, PRONEX project, Brazil). Diogo Moreira holds a CNPq scholarship. The authors acknowledge the technical assistance of José Fernando Costa (FIOCRUZ, Brazil) in the cytotoxicity assays.

\section{Supplementary data}

Supplementary data (compound characterization of the compounds outlined in Scheme 1. Pharmacological protocols conducted can also be found in the Supporting Information) associated with this article can be found, in the online version, at doi:10.1016/j.bmc.2010.07.039.

\section{References and notes}

1. World Health Organization Reports, last access in April 2010, at http:// www.who.int/malaria/en/.

2. Mahomva, A. I.; Peterson, D. E.; Rakata, L. Cent. Afr. J. Med. 1996, 42, 345

3. Bustamante, C.; Batista, C. N.; Zalis, M. Curr. Drug Targets 2009, 10, 279.

4. Stanley, S. L., Jr. Lancet 2003, 361, 1025.

5. (a) Adagu, I. S.; Nolder, D.; Warhurst, D. C.; Rossignol, J. F. J. Antimicrob. Chemother. 2002, 49, 103; (b) Singh, S.; Bharti, N.; Mohapatra, P. P. Chem. Rev. 2009, 109, 1900.

6. Lu, J. Z.; Lee, P. J.; Waters, N. C.; Prigge, S. T. Comb. Chem. High Throughput Screen. 2005, 8, 15

7. Tekwani, B. L.; Walker, L. A. Comb. Chem. High Throughput Screen. 2005, 8, 63.

8. Kerr, I. D.; Lee, J. H.; Farady, C. J.; Marion, R.; Rickert, M.; Sajid, M.; Pandey, K. C.; Caffrey, C. R.; Legac, J.; Hansell, E.; McKerrow, J. H.; Craik, C. S.; Rosenthal, P. J.; Brinen, L. S. J. Biol. Chem. 2009, 284, 25697.

9. Canduri, F.; Perez, P. C.; Caceres, R. A.; Azevedo, W. F., Jr. Curr. Drug Targets 2007, 8, 389.

10. Silva, R. G.; Nunes, J. E.; Canduri, F.; Borges, J. C.; Gava, L. M.; Moreno, F. B.; Basso, L. A.; Santos, D. S. Curr. Drug Targets 2007, 8, 413.

11. Bajsa, J.; Duke, S. O.; Tekwani, B. L. Curr. Drug Targets 2008, 9, 997.

12. Lima, L. M.; Barreiro, E. J. Curr. Med. Chem. 2005, 12, 23.

13. Viegas-Junior, C.; Danuello, A.; Bolzani, V. S.; Barreiro, E. J.; Fraga, C. A. M. Curr. Med. Chem. 2007, 14, 103.

14. Gelb, M. H.; Van Voorhis, W. C.; Buckner, F. S.; Yokoyama, K.; Eastman, R.; Carpenter, E. P.; Panethymitaki, C.; Brown, K. A.; Smith, D. F. Mol. Biochem. Parasitol. 2005, 126, 155.

15. Sanchez-Delgado, R. A.; Anzellotti, A. Mini. Rev. Med. Chem. 2004, 4, 23.

16. For excellent reviews of bioactive metallic structures, see: (a) Beraldo, $\mathrm{H}$; Gambino, D. Mini. Rev. Med. Chem. 2004, 4, 31; (b) Storr, T.; Thompson, K. H.; Orvig, C. Chem. Soc. Rev. 2006, 35, 534; (c) Fricker, S. P. Dalton Trans. 2007, 4903; (d) Dive, D.; Biot, C. ChemMedChem 2008, 3, 383.
17. A survey of metallic structures endowed with antiplasmodium properties: (a) Sanchez-Delgado, R. A.; Navarro, M.; Perez, H.; Urbina, J. A. J. Med. Chem. 1996, 39, 1095; (b) Harpstrite, S. E.; Beatty, A. A.; Collins, S. D.; Oksman, A.; Goldberg, D. E.; Sharma, V. Inorg. Chem. 2003, 42, 2294; (c) Navarro, M.; Vasquez, F.; Sanchez-Delgado, R. A.; Perez, H.; Sinou, V.; Schrevel, J. J. Med. Chem. 2004, 47, 5204; (d) Gokhale, N. H.; Shirisha, K.; Padhye, S. B.; Croft, S. L.; Kendrick, H. D.; Mckee, V. Bioorg. Med. Chem. 2006, 16, 430; (e) Martínez, A.; Rajapakse, C. S. K.; Naoulou, B.; Kopkalli, Y.; Davenport, L.; Sanchez-Delgado, R. A. J. Biol. Inorg. Chem. 2008, 13, 703; (f) Gabbiani, C.; Messori, L.; Cinellu, M. A.; Casini, A. Mura, P.; Sannella, A. R.; Severini, C.; Majori, G.; Bilia, A. R.; Vincieri, F. F. J. Inorg. Biochem. 2009, 103, 310; (g) Schuh, E.; Valiahdi, S. M.; Jakupec, M. A.; Keppler, B. K.; Chiba, P.; Mohr, F. Dalton Trans. 2009, 10841; (h) Rajapakse, C. S. K.; Martinez, A.; Naoulou, B.; Jarzecki, A. A.; Suarez, L.; Deregnaucourt, C.; Sinou, V.; Schrevel, J.; Musi, E.; Ambrosini, G.; Schwartz, G. K.; Sanchez-Delgado, R. A Inorg. Chem. 2009, 48, 1122; (i) Adediji, J. F.; Olayinka, E. T.; Adebayo, M. A.; Babatunde, O. Int. J. Phys. Sci. 2009, 4, 529; (j) Soares, M. B. P.; Costa, J. F. O.; de Sá, M. S.; Ribeiro-dos-Santos, R.; Jaouen, G.; Santana, A. E. G.; Goulart, M. O. F.; Hillard, E. Drug Dev. Res. 2010, 71, 69.

18. (a) Cerecetto, H.; Gonzalez, M. Mini Rev. Med. Chem. 2008, 8, 1355; (b) Donnici, C. L.; Araújo, M. H.; Oliveira, H. S.; Moreira, D. R. M.; Pereira, V. R. A.; Souza, M. de A.; De Castro, M. C. A. B.; Leite, A. C. L. Bioorg. Med. Chem. 2009, 17, 5038

19. (a) Rebolledo, A. P.; Vieites, M.; Gambino, D.; Piro, O. E.; Castellano, E. E.; Zani, C. L.; Souza-Fagundes, E. M.; Teixeira, L. R.; Batista, A. A.; Beraldo, H. J. Inorg. Biochem. 2005, 99, 698; (b) Yu, Y.; Kalinowski, D. S.; Kovacevic, K.; Siafakas, A. R.; Jansson, P. J.; Stefani, C.; Lovejoy, D. B.; Bernhardt, P. V.; Richardson, D. R. J. Med. Chem. 2009, 52, 5271; (c) Bernhardt, P. V.; Sharpe, P. C.; Islam, M. Lovejoy, D. B.; Kalinowski, D. S.; Richardson, D. R. J. Med. Chem. 2009, 52, 407.

20. Duarte, C. D.; Barreiro, E. J.; Fraga, C. A. M. Mini Rev. Med. Chem. 2007, 7, 1108

21. (a) Shailendra, N.; Bharti, N.; Naqvi, F.; Azam, A. Bioorg. Med. Chem. Lett. 2003 13, 689; (b) Singh, S.; Athar, F.; Maurya, M. R.; Azam, A. Eur. J. Med. Chem. 2006, $41,592$.

22. (a) Abid, M.; Azam, A. Bioorg. Med. Chem. 2005, 13, 2213; (b) Abid, M.; Bhat, A R.; Athar, F.; Azam, A. Eur. J. Med. Chem. 2009, 44, 417.

23. Abid, M.; Agarwal, S. M.; Azam, A. Eur. J. Med. Chem. 2008, 43, 2035.

24. (a) Greenbaum, D. C.; Mackey, Z.; Hansell, E.; Doyle, P.; Gut, J.; Caffrey, C. R.; Lehrman, J.; Rosenthal, P. J.; McKerrow, J. H.; Chibale, K. J. Med. Chem. 2004, 47 3212; (b) Biot, C.; Pradines, B.; Sergeant, M.-H.; Gut, J.; Rosenthal, P. J.; Chibale, K. Bioorg. Med. Chem. Lett. 2007, 17, 6434; (c) Oliveira, R. B.; de Souza-Fagundes, E. M.; Soares, R. P. P.; Andrade, A. A.; Krettli, A. U.; Zani, C. L. Eur. J. Med. Chem. 2008, 43, 1983; (d) Mallari, J. P.; Guiguemde, W. A.; Guy, R. K. Bioorg. Med. Chem. Lett. 2009, 19, 3546.

25. Scovill, J. P.; Klayman, D. L.; Franchino, C. F. J. Med. Chem. 1982, 25, 1261.

26. (a) Stump, B.; Kaiser, M.; Brun, R.; Krauth-Siegel, R. L.; Diederich, F. ChemMedChem 2007, 2, 1708; (b) Rodríguez-Argüelles, M. C.; TourónTouceda, P.; Cao, R.; García-Deibe, A. M.; Pelagatti, P.; Pelizzi, C.; Zani, F. J. Inorg. Biochem. 2009, 103, 21; (c) Moreira, D. R. M.; Leite, A. C. L.; Santos, R. R.; Soares, M. B. P. Curr. Drug Targets 2009, 10, 212.

27. Padhye, S.; Afrasiabi, Z.; Sinn, E.; Fok, J.; Mehta, K.; Rath, N. Inorg. Chem. 2005 $44,1154$.

28. Sharma, S.; Athar, F.; Maurya, M. R.; Azam, A. Eur. J. Med. Chem. 2005, 40, 1414.

29. Li, Q.; Tang, H.; Li, Y.; Wang, M.; Wang, L.; Xia, C. J. Inorg. Biochem. 2000, 78, 167.

30. Singh, V. P.; Katiyar, A.; Singh, S. Biometals 2008, 21, 491.

31. Singh, B.; Yadava, B.; Aggarwal, R. C. Indian J. Chem. 1984, 23A, 441.

32. Navarro, M.; Cisneros-Fajardo, E. J.; Sierralta, A.; Fernandez-Mestre, M.; Arrieche, P. S. D.; Marchan, E. J. Biol. Inorg. Chem. 2003, 8, 401.

33. Jones, R.; Summerville, D.; Basolo, F. Chem. Rev. 1979, 79, 139.

34. (a) Ferraz, K. S. O.; Ferandes, L.; Carrilho, D.; Pinto, M. C. X.; Leite, M. F.; SouzaFagundes, E. M.; Speziali, N. L.; Mendes, I. C.; Beraldo, H. Bioorg. Med. Chem. 2009, 17, 7138; (b) Aghatabay, N. B.; Somer, M.; Senela, M.; Dulger, B.; Gucin, F. Eur. J. Med. Chem. 2007, 42, 1069.

35. Martinez, A.; Rajapakse, C. S. K.; Jalloh, D.; Dautriche, C.; Sanchez-Delgado, R. A. J. Biol. Inorg. Chem. 2009, 14, 863.

36. Espinosa, A.; Perdrizet, G.; Mino, G. P.; Phay, M. J. Antimicrob. Chemother. 2009, $63,675$.

37. Osullivan, D. G.; Sadler, P. W.; Webley, C. Chemotherapia 1963, 7, 17.

38. Price, J. H.; Williamson, A. N.; Schramm, R. F.; Wayland, B. B. Inorg. Chem. 1972 $116,1280$.

39. de Sá, M. S.; Costa, J. F. O.; Krettli, A. U.; Zalis, M. G.; Maia, G. L. A.; Sette, I. M. F.; Camara, C. A.; Filho, J. M. B.; Harley, A. M. G.; dos Santos, R. R.; Soares, M. B. P. Parasitol. Res. 2009, 105, 275.

40. Wright, C. W.; O'neill, M. J.; Phillipson, J. D.; Warhurst, D. C. Antimicrob. Agents Chemother. 1988, 32, 1725.

41. Diamond, L. S.; Harlow, D. R.; Cunnick, L. S. Trans. R. Soc. Trop. Med. Hyg. 1978, $72,431$. 